\title{
The Jejunal Secretory Response to Escherichia coli Heat-Stable Enterotoxin is Prolonged in Malnourished Rats
}

\author{
MITCHELL B. COHEN, JOSEPH NOGUEIRA, D. WAYNE LANEY, JR., AND TERRANCE R. CONTI \\ Division of Pediatric Gastroenterology and Nutrition, Children's Hospital Research Foundation, and the \\ University of Cincinnati, Cincinnati, Ohio 45229
}

\begin{abstract}
Undernutrition in human infants is associated with more prolonged episodes of diarrheal disease. Therefore, we tested the hypothesis that malnutrition prolongs the duration of Escherichia coli heat-stable enterotoxin-induced rat jejunal secretion. At weaning, rats were separated into two groups: malnourished rats were fed $\mathbf{5 0} \%$ of the previous day's intake of the fully fed control group. After approximately 2 wk of pair feeding, when malnourished rats weighed $\leq 60 \%$ of the full fed control group, we measured the secretory response to heat-stable enterotoxin in ligated jejunal loops. Toxin-induced secretion was equal in both groups until 30 min incubation time, after which net secretion continued to increase in the malnourished group but decreased in the fully fed group. Jejunal brush border membranes prepared from malnourished and fully fed rats demonstrated similar heat-stable enterotoxin receptor density, avidity of binding and guanyl cyclase activation. In both groups, radiolabeled toxin injected into in situ jejunal loops was converted into an altered radioligand unable to bind to brush border membranes. However, in malnourished rats, there was both increased appearance of two additional radioligands that still retained their ability to bind to brush border membranes and persistence of biologically active unlabeled toxin as measured in the suckling mouse bioassay. Our studies demonstrate that reduced or delayed inactivation of heat-stable enterotoxin, with continued presence of active toxin species, may contribute to prolonged secretion in the jejunum of malnourished rats. (Pediatr Res 31: 228-233, 1992)
\end{abstract}

\section{Abbreviations}

ETEC, enterotoxigenic Escherichia coli

$\mathrm{ST}_{\text {a }}$, Escherichia coli heat-stable enterotoxin

BBM, brush border membrane

$K_{a}$, apparent affinity constant of binding

FF, fully fed control group

MAL, malnourished group

cGMP, cyclic GMP

Diarrheal disease is one of the most important health problems in developing areas of the world, accounting for up to $50 \%$ of

Received March 1, 1991; accepted November 11, 1991.

Correspondence and reprint requests: Mitchell B. Cohen, M.D., Division of Pediatric Gastroenterology, Children's Hospital Medical Center, 3250 Elland Avenue, Cincinnati, OH 45229-2899.

Supported in part by an American Gastroenterological Association/Glaxo Industry Award and by U.S. Public Health Service Grant DK-01908. This work was presented in part at the annual meeting of the SPR/APS in Washington, DC, May 1989, and published in abstract form in Pediatr Res 25:110A, 1989. infant mortality and an estimated five million deaths per year in children under 5 y of age (1-5). Malnutrition is a major coexisting health problem in children in these developing areas, with an estimated prevalence of $30-90 \%(6-8)$. These two problems appear to be mutually aggravating; recurrent episodes of diarrhea adversely affect the nutritional status of children, and diarrheal disease may be more frequent and more prolonged in malnourished children $(6-11)$.

Infection with ETEC is among the most common causes of endemic childhood diarrhea $(2,12-14)$. These ETEC elaborate several enterotoxins including $\mathrm{ST}_{\mathrm{a}}$, which is a small polypeptide that is able to activate guanylate cyclase, induce intestinal secretion, and cause diarrheal disease (15-17).

The aim of our study was to determine the effect of malnutrition on $\mathrm{ST}_{\mathrm{a}}$-mediated intestinal secretion. To test our hypothesis that the malnourished rat was more responsive to $\mathrm{ST}_{\mathrm{a}}$, we compared the in situ secretory response to $\mathrm{ST}_{\mathrm{a}}$ in the jejunum of malnourished and fully fed rats. We also examined potential mechanisms that could account for increased responsiveness to $\mathrm{ST}_{\mathrm{a}}$ in the malnourished rat. To do this, we compared l) $\mathrm{ST}_{\mathrm{a}}-$ binding, 2) $\mathrm{ST}_{\mathrm{a}}$-induced guanylate cyclase activation, and 3) inactivation of $\mathrm{ST}_{\mathrm{a}}$ in the jejunum of the malnourished and fully fed rat.

\section{MATERIALS AND METHODS}

$S T_{\mathrm{a}}$ and $4-T y r_{-}{ }^{125} I-S T_{\mathrm{a}} . \mathrm{ST}_{\mathrm{a}}$ from $E$. coli strain $18 \mathrm{D}$ was purified as described by Staples et al. (18). $\mathrm{Na}^{125} \mathrm{I}(>350 \mathrm{mCi} /$ $\mathrm{mL}$ ) was obtained from Amersham (Arlington Heights, IL) and was used to radioiodinate pure $\mathrm{ST}_{\mathrm{a}}$ by a lactoperoxidase method (19). 4-Tyr- ${ }^{125} \mathrm{I}_{-} \mathrm{ST}_{\mathrm{a}}$ was purified by HPLC (19).

Animals. Twenty- to 21-d-old Sprague-Dawley rats (10-11 pups/litter), with mothers, were obtained from Zivic Miller Laboratories (Zelienople Park, PA). Animals were housed at the University of Cincinnati, and the experimental protocol was approved by the Institutional Animal Care and Use Committee. This facility is accredited by the American Association for Accreditation of Laboratory Animal Care. Rats were housed in wire-mesh cages to prevent coprophagia and were maintained in $22^{\circ} \mathrm{C}$ temperature-controlled rooms with 12 -h alternating lightdark cycles. They were allowed water ad libitum throughout the study. All rats were fed standard laboratory food from hanging metal food baskets.

Animals were rendered malnourished using a modification of the pair-feeding technique described by Sherman et al. (20). Rat pups were fed ad libitum for the first day after weaning and were then randomly assigned to either the FF or the MAL. The group of animals assigned to MAL were each day allotted $50 \%$ of the average intake for the previous day for the group of animals in FF. Our studies were performed when the average body weight of MAL was approximately $60 \%$ of that of FF.

In situ intestinal secretion. After intraperitoneal sodium pen- 
tobarbital anesthesia, one or two sections of intestine beyond the ligament of Treitz of approximately $10 \mathrm{~cm}$ (proximal jejunum) were isolated with surgical ligatures as previously described (21). Pure $\mathrm{ST}_{\mathrm{a}}(10 \mu \mathrm{g} / \mathrm{mL})$ in $1 \mathrm{~mL}$ of saline or an equal volume of $\mathrm{ST}_{\mathrm{a}}$-free saline was injected into each loop with a 30-gauge needle. After in situ incubation for 15-240 min, the abdomen was reopened and the ligated loop was removed and weighed intact. The loop was opened, milked dry of accumulated fluid, and weighed empty. Net fluid accumulation was calculated as the difference between the weight intact and the weight empty. Secretion is expressed as fluid accumulation in an $\mathrm{ST}_{\mathrm{a}}$-containing loop minus fluid accumulation in a control $\left(\mathrm{ST}_{\mathrm{a}}-\mathrm{free}\right)$ loop. The data were expressed in $\mu \mathrm{L} / \mathrm{cm}$ intestinal loop length. Expressing the data in $\mathrm{mL} / \mathrm{g}$ intestinal loop weight gave similar results.

To evaluate the inactivation of the $\mathrm{ST}_{\mathrm{a}}$ remaining in the secreted fluid, some animals were injected with $4-\mathrm{Tyr}^{125}{ }^{125} \mathrm{ST}_{\mathrm{a}}$ $(50-250 \mathrm{pM})$ and the secreted fluid was harvested at various times as previously described (22). Radiolabeled $\mathrm{ST}_{\mathrm{a}}$ remaining in secreted fluid was characterized by HPLC and by the ability to rebind to rat jejunal BBM as previously described (22). In addition, biologic activity of unlabeled $\mathrm{ST}_{\mathrm{a}}$ in secreted fluid was determined in the suckling mouse assay as previously described $(22,23)$.

$B B M$ preparation. Jejunal BBM were prepared using a modification of the divalent cation precipitation technique described by Schmitz et al. (24) as previously validated in our laboratory (21). After preparation, BBM were promptly frozen in a $-80^{\circ} \mathrm{C}$ freezer and stored for 1-3 wk. Sucrase enrichment was comparable for both groups (14.9- \pm 0.69 - and 16.8- \pm 3.7 -fold increase over jejunal homogenate for MAL and FF, respectively). Protein concentration was measured by the method of Lowry et al. (25) using BSA as the standard. DNA was quantitated by the method of Brunk et al. (26).

Binding of $S T_{\mathrm{a}}$ to $B B M$. A competitive inhibition of binding assay was used to characterize the binding of $\mathrm{ST}_{\mathrm{a}}$ to $\mathrm{BBM}$ as previously described $(21,22)$. Briefly, BBM $(60-90 \mu \mathrm{g})$ were incubated with a constant amount of ${ }^{125}{ }^{12}-\mathrm{ST}_{\mathrm{a}}$ (approximately $45000 \mathrm{cpm})$ and varying amounts of unlabeled $\mathrm{ST}_{\mathrm{a}}(0.05-1000$ $\mathrm{ng}$ ) in $0.1 \mathrm{M}$ sodium acetate, $\mathrm{pH} 4.8$, with $0.15 \% \mathrm{BSA}$. The incubation at $37^{\circ} \mathrm{C}$ was terminated after 60 min by rapid suction filtration. Specific binding was determined by subtracting the binding of 4-Tyr- ${ }^{125} \mathrm{I}_{-} \mathrm{ST}_{\mathrm{a}}$ in the presence of $>1000$-fold excess unlabeled $\mathrm{ST}_{\mathrm{a}} \cdot \mathrm{K}_{\mathrm{a}}$ and the binding capacity were calculated by Scatchard analysis, using the least-squares-fit computer program "Ligand" as described by Munson and Rodbard (27).

Guanylate cyclase activation. $\mathrm{ST}_{\mathrm{a}}$-induced guanylate cyclase activation was determined using the technique described by Waldman et al. (28). $\mathrm{ST}_{\mathrm{a}}$-stimulated guanylate cyclase activity was expressed in pmol cGMP generated per $\mathrm{mg}$ membrane protein per min and compared with basal, unstimulated activity.

Suckling mouse assay. Biologic activity of $\mathrm{ST}_{\mathrm{a}}$ in secreted fluid was determined in the suckling mouse assay (29). Three ND4 Swiss albino mice were inoculated by percutaneous intragastric injection with $100 \mu \mathrm{L}$ of secreted fluid. Three $\mathbf{h}$ after inoculation, the mice were killed and the intestine without the stomach was removed and weighed. The ratio of gut-to-carcass weight was calculated.

Northern analysis. Total RNA was isolated from rat jejunum by the guanidine isothiocyanate method (30). An aliquot was used in a reverse transcription reaction containing an antisense primer based on the rat guanyl cyclase C cDNA sequence (31). The resulting cDNA was then used as a template for the polymerase chain reaction (Perkin Elmer Cetus, Norwalk, CT). The product of this reaction, a fragment encompassing nucleotides 54-602 of the rat guanyl cyclase C cDNA (31), was cloned into Bluescript (Stratagene, La Jolla, CA) by blunt ligation. The identity of the recombinant clone ( $\mathrm{p} 5^{\prime} \mathrm{GC}-\mathrm{C}$ ) was confirmed by sequence analysis (32).

Total RNA was then prepared from the jejunum of MAL and FF (30). For Northern blots, total RNA $(20 \mu \mathrm{g})$ was denatured with glyoxal, fractionated on a $1 \%$ agarose gel, and transferred to a nylon membrane by capillary action. Blots were cross-linked with short-wave UV, dried, and washed at $65^{\circ} \mathrm{C}$ in $1 \times \mathrm{SSC}$ (SSC is $0.15 \mathrm{M}$ sodium chloride/0.015 $\mathrm{M}$ sodium citrate, $\mathrm{pH} 7.6$ ), $0.1 \%$ SDS. Prehybridization was performed as described by Church and Gilbert (33).

The $\mathrm{p} 5^{\prime} \mathrm{GC}-\mathrm{C}$ fragment of the rat guanyl cyclase $\mathrm{C}$ was radiolabeled with $\left[\alpha{ }^{32} \mathrm{P}\right]$ deoxycytidine triphosphate by random primer extension (34) and hybridized under stringent conditions with final wash conditions of $0.1 \times \mathrm{SSC}, 0.5 \% \mathrm{SDS}$ at $65^{\circ} \mathrm{C}$. Autoradiography was performed at $-80^{\circ} \mathrm{C}$ with XAR-5 film (Eastman Kodak Co., Rochester, NY) using Cronex Lightening Plus intensifying screens (New England Nuclear, Boston, MA). Densitometric analysis of the autoradiograms was obtained using a laser densitometer (LKB Instruments, Inc., Gaithersburg, MD). The autoradiographic values were normalized based on the signal intensity seen upon hybridization with an oligonucleotide complementary to $18 \mathrm{~S}$ ribosomal RNA (35).

Data presentation and analysis. For in situ experiments, each point represents the mean of three to 11 determinations. For $\mathrm{ST}_{\mathrm{a}}$-binding and $\mathrm{ST}_{\mathrm{a}}$-stimulated guanylate cyclase experiments, each point was determined in duplicate and experiments were repeated in triplicate. All data are presented as mean \pm SEM. Paired comparisons were performed using the $t$ test and, when appropriate, the Wilcoxon rank sum test was used for unpaired comparisons.

\section{RESULTS}

Pair feeding. Nutritional deprivation by pair feeding markedly reduced the growth of malnourished rats. The average daily weight gain during the pair-feeding period was $9.7 \mathrm{~g}$ for $\mathrm{FF}$, whereas that for MAL was $5.7 \mathrm{~g}$. The mean duration of pair feeding was $17.4 \pm 0.5 \mathrm{~d}$. The weight of the animals when they were killed was $174.5 \pm 3.3 \mathrm{~g}$ for FF $(n=95)$ and $100.9 \pm 3.1 \mathrm{~g}$ for MAL $(n=95)$, the ratio of MAL/FF weight being 0.58 .

Effects of malnutrition on the intestine. As shown in Table 1 , the MAL intestine weighed less and was significantly shorter than FF intestine. However, the weight of the intestine was approximately $4.5 \%$ of the total body weight in each group. Sucrase activity was significantly increased in MAL jejunum. Jejunal protein content and jejunal DNA content were reduced in MAL but these differences were not statistically significant.

In situ intestinal secretion. The time course of the net secretory response to a $10-\mu \mathrm{g} / \mathrm{mL}$ dose of intraluminal $\mathrm{ST}_{\mathrm{a}}$ is shown in Figure 1. At all times, the response in the saline control loops for FF and MAL was similar (data not shown). The net secretory response to $\mathrm{ST}_{\mathrm{a}}$ was similar in FF and MAL until 30 min of incubation, after which time net secretion continued to increase in MAL but decreased in FF. By 240 min, the last time point tested, net secretion in MAL was nearly 10 -fold that of the FF (236 \pm 22 versus $24 \pm 15 \mu \mathrm{L} / \mathrm{cm}$, respectively, $p=0.005$ ). If a tissue weight basis was used to normalize the data, the difference became even more marked $(5.51 \pm 0.55$ versus $0.25 \pm 0.21 \mathrm{~mL} /$ $\mathrm{g}$ intestine, $p<0.001$ at $240 \mathrm{~min}$ ).

$S T_{\mathrm{a}}$ binding to $B B M$. To determine whether the differences in the number of $\mathrm{ST}_{\mathrm{a}}$ receptors or avidity of $\mathrm{ST}_{\mathrm{a}}$ binding might explain this observed difference in response to $\mathrm{ST}_{a}$, we calculated

Table 1. Effect of malnutrition on intestinal weight, length, and sucrase activity

\begin{tabular}{lccc}
\hline & FF & MAL & $p$ \\
\hline Intestinal weight $(\mathrm{g})$ & $6.69 \pm 0.30$ & $4.01 \pm 0.26$ & $<0.001$ \\
Intestinal length $(\mathrm{cm})$ & $108 \pm 3.9$ & $89.4 \pm 4.3$ & 0.01 \\
Intestinal weight/body & $0.046 \pm 0.006$ & $0.045 \pm 0.005$ & 0.86 \\
$\quad$ & & & \\
$\quad$ weight & $49.5 \pm 10.2$ & $124.5 \pm 17.5$ & 0.02 \\
Sucrase activity $(\mathrm{mU})$ & $4.7 \pm 0.7$ & $3.4 \pm 0.3$ & 0.10 \\
Jejunal protein $(\mathrm{mg} / \mathrm{cm})$ & $626 \pm 61.7$ & $478 \pm 89.6$ & 0.17 \\
Jejunal DNA $(\mu \mathrm{g} / 5 \mathrm{~cm})$ & & & \\
\hline
\end{tabular}




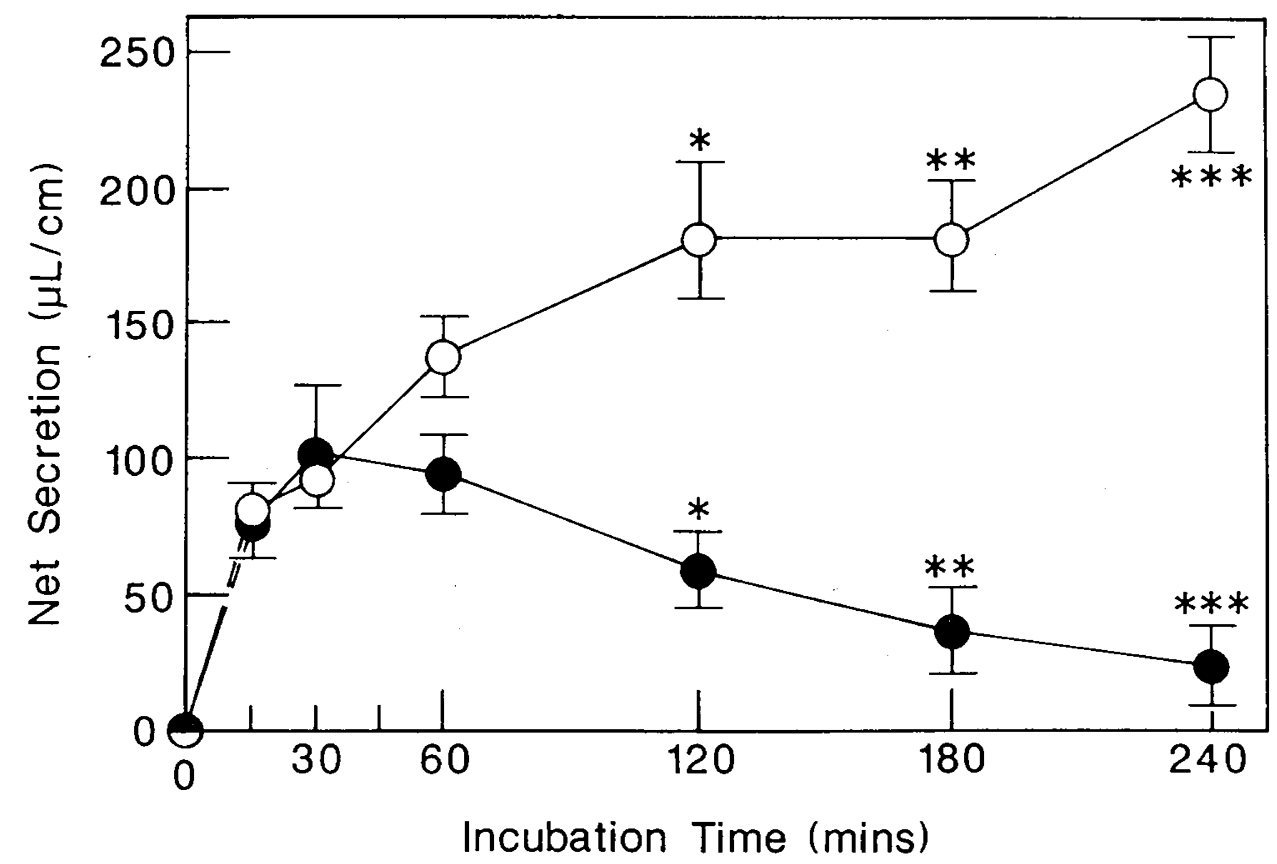

Fig. 1. Time course of net jejunal secretion in response to a $10-\mu \mathrm{g} / \mathrm{mL}$ dose of intraluminal $\mathrm{ST}_{\mathrm{a}}$. Net secretion in MAL (open circles) and $\mathrm{FF}$ ( filled circles) rats was measured as described in Materials and Methods and calculated as fluid accumulation in a test loop minus fluid accumulation in a control loop. The response to a (control) injection was identical in MAL and FF rats. Data are mean \pm SEM of three to 11 determinations. *, $p<0.01$ at $120 \mathrm{~min} ; * *, p<0.001$ at $180 \mathrm{~min} ; * * *, p=0.005$ at $240 \mathrm{~min}$.

the $\mathrm{K}_{\mathrm{a}}$ of $\mathrm{ST}_{\mathrm{a}}$ binding and number of $\mathrm{ST}_{\mathrm{a}}$ receptors per mg protein in BBM preparations from FF and MAL. As shown in Figure 2, increasing doses of unlabeled $\mathrm{ST}_{\mathrm{a}}$ progressively and identically inhibited the binding of ${ }^{125} \mathrm{I}_{-} \mathrm{ST}_{\mathrm{a}}$ to jejunal BBM of FF and MAL. The data from these assays were used to calculate the $\mathrm{K}_{\mathrm{a}}$ of ${ }^{125} \mathrm{I}_{-} \mathrm{ST}_{\mathrm{a}}$ binding which was similar for both MAL and $\mathrm{FF}\left(2.48 \pm 0.56 \times 10^{9}\right.$ versus $1.81 \pm 0.50 \times 10^{9} \mathrm{~L} / \mathrm{mol}$, respectively). The number of $\mathrm{ST}_{\mathrm{a}}$ receptors per mg BBM protein was also identical for MAL and FF $\left(3.34 \pm 0.99 \times 10^{12}\right.$ versus 3.12 $\pm 0.87 \times 10^{12}$, respectively). When normalized by DNA content, $\mathrm{ST}_{\mathrm{a}}$ binding was similar in mucosal homogenates from MAL and FF $(2273 \pm 670$ versus $2346 \pm 657 \mathrm{cpm}$ per $\mu \mathrm{g}$ DNA, respectively).

Guanylate cyclase activation. To determine if increased receptor-effector coupling played a role in the increased responsiveness of the malnourished rat jejunum to $\mathrm{ST}_{\mathrm{a}}$, we measured jejunal guanylate cyclase activity at basal levels and in response to increasing doses of $\mathrm{ST}_{\mathrm{a}}$ in FF and MAL. As seen in the doseresponse curves shown in Figure 3 , increasing quantities of $\mathrm{ST}_{a}$ progressively and identically activated guanylate cyclase, resulting in a similar $\mathrm{ED}_{50}(1-4 \mathrm{ng})$ and maximal stimulation (4.5fold) in MAL and FF. Basal guanylate cyclase levels were similar in both MAL and FF $(10.3 \pm 2.0$ versus $15.0 \pm 5.5$ pmol cGMP/ $\mathrm{mg} / \mathrm{min}$, respectively).

$S T_{\text {a }}$ receptor $m R N A$ expression. Northern analysis was used to examine the expression of the $\mathrm{ST}_{\mathrm{a}}$ receptor in MAL and FF. As shown in Figure 4, upon hybridization with a radiolabeled fragment of the $\mathrm{ST}_{\mathrm{a}}$ receptor cDNA, a 3.8-kb message is seen in both MAL and FF. When quantitated by laser densitometry and normalized by $18 \mathrm{~S}$ RNA signal, the $\mathrm{ST}_{\mathrm{a}}$ receptor mRNA expression was equal in both groups.

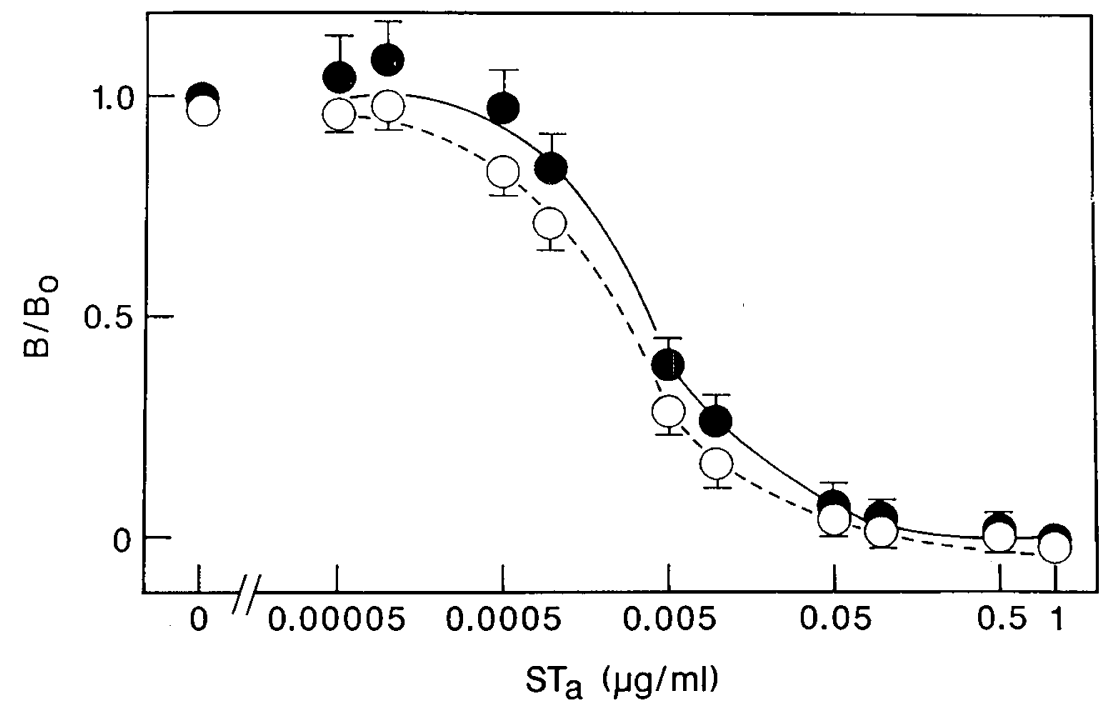

Fig. 2. Effect of increasing doses of unlabeled $\mathrm{ST}_{\mathrm{a}}$ on binding of ${ }^{125} \mathrm{I}_{-\mathrm{ST}}$ to BBM from MAL (open circles) and FF (filled circles) rats. Binding of ${ }^{125} \mathrm{I}-\mathrm{ST}_{\mathrm{a}}$ was similar in both groups. Data are mean $\pm \mathrm{SEM}$ of three separate experiments. $B / B_{0}$, fraction of ${ }^{125} \mathrm{I}-\mathrm{ST}_{\mathrm{a}}$ bound in the absence of added, unlabeled toxin. 


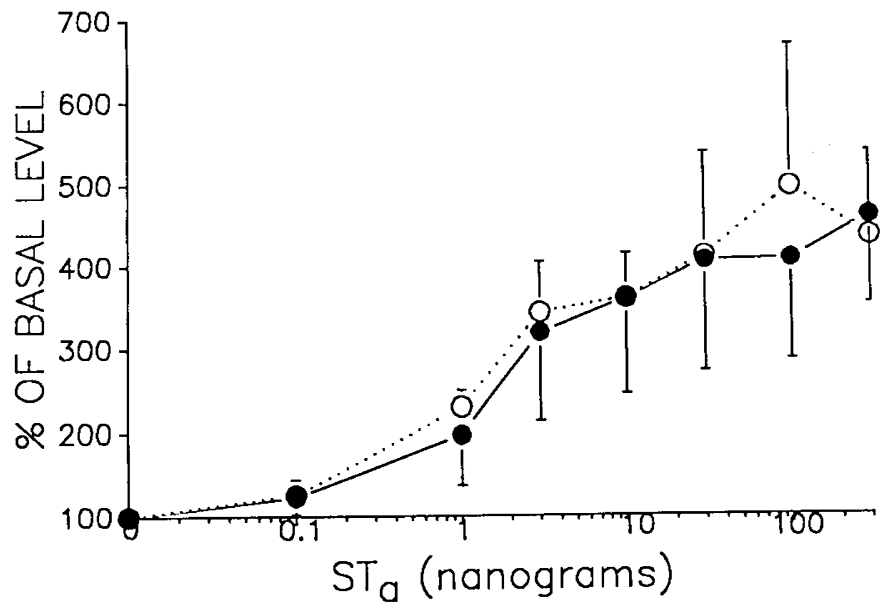

Fig. 3. Effect of increasing doses of $\mathrm{ST}_{\mathrm{a}}$ on guanylate cyclase activation in BBM from MAL (open circles) and FF (filled circles) rats. Maximal guanylate cyclase activation and $\mathrm{ED}_{50}$ were identical in $\mathrm{MAL}$ and FF rats. Data are mean \pm SEM of three separate determinations. Data are expressed as the percentage of guanylate cyclase activation in the absence of added $\mathrm{ST}_{\mathrm{a}}$.

\section{FF MAL}

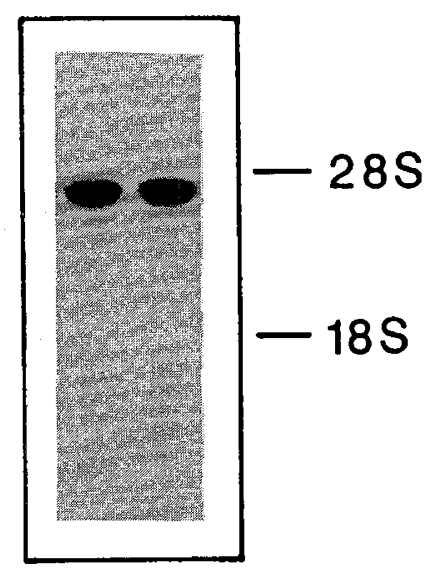

\section{FF MAL}

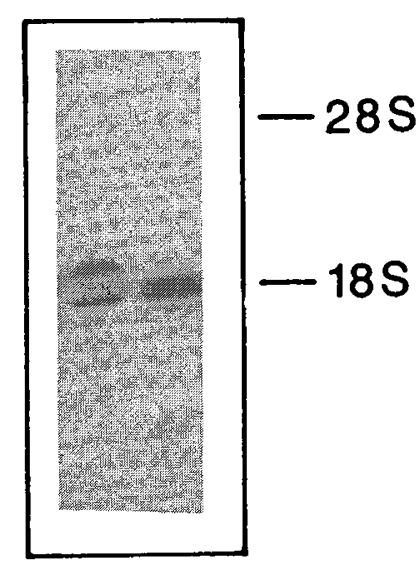

Fig. 4. Northern blot analysis of $\mathrm{ST}_{\mathrm{a}}$ receptor expression in the jejunum of FF and MAL rats. Migration of $28 \mathrm{~S}$ and $18 \mathrm{~S}$ ribosomal RNA is shown on the right. For normalization of the signal intensity, hybridization with an oligonucleotide complementary to $18 \mathrm{~S}$ ribosomal RNA was performed and is shown below.
HPLC profile and BBM binding characteristics of recovered radioactivity. A comparison of the time course of disappearance of radioactivity from MAL and FF jejunum is shown in Figure 5. In both groups, there was continued disappearance of radioactivity over time. At all time points, the percentage of remaining radioactivity was greater in MAL, but at no time point was this difference statistically significant.

To determine whether alteration of the injected radiolabeled $\mathrm{ST}_{\mathrm{a}}$ had occurred, we evaluated the HPLC profiles of the fluid recovered from the jejunal loops of MAL and FF. Figure 6 shows a representative HPLC profile of ${ }^{125}{ }^{2}-\mathrm{ST}_{\mathrm{a}}$ after a 30 -min in situ incubation. Arrows point to those peaks that comigrate with the injected authentic 4-Tyr- ${ }^{125} \mathrm{I}_{-} \mathrm{ST}_{\mathrm{a}}$. Shown above the chromatograms are the BBM binding activities of the corresponding HPLC peaks. In both FF and MAL, there was a major new peak with a shortened retention time $(5 \mathrm{~min})$, representing $98.4 \pm 1.4 \%$ of the remaining radiotracer in $\mathrm{FF}$ and $61.1 \pm 10.3 \%$ in MAL ( $p$ $<0.001$ ). This modified radiotracer had lost the ability to bind to BBM. However, in MAL jejunum there was an increased appearance of two other peaks with retention times closer to that of authentic 4-Tyr- ${ }^{125} \mathrm{I}_{-\mathrm{ST}}$. These peaks, with HPLC retention times of 24 and $27 \mathrm{~min}$, represented $27.7 \pm 10.5$ and $11.1 \pm$ $2.4 \%$, respectively, of the remaining radiotracer in MAL jejunum and $1.6 \pm 1.4(p=0.001)$ and $0 \pm 0(p=0.02)$ of the remaining radiotracer in FF jejunum. Both of these peaks (24 and $27 \mathrm{~min}$ ) retained their ability to bind to $\mathrm{BBM}$, unlike the major peak identified at $5 \mathrm{~min}$. By $60 \mathrm{~min}$ incubation, virtually all of the remaining radiotracer in both groups had been converted to a radiolabel with a retention time of 5-10 min.

Suckling mouse assay. We evaluated the biologic activity of $\mathrm{ST}_{\mathrm{a}}$ and its metabolites remaining in secreted fluid by determining the ability of MAL and FF jejunal fluid to stimulate secretion in the suckling mouse assay. A gut-to-carcass ratio of $\geq 0.083$ was considered positive. Jejunal fluid from MAL was positive from the 30-, 60-, 120-, and 180-min time points, but negative at the 240-min incubation time point. In contrast, jejunal fluid from $\mathrm{FF}$ was positive at $30 \mathrm{~min}$, but negative at $60 \mathrm{~min}$ and all subsequent time points.

\section{DISCUSSION}

A number of studies have demonstrated that there is a direct relationship between malnutrition and the severity and duration

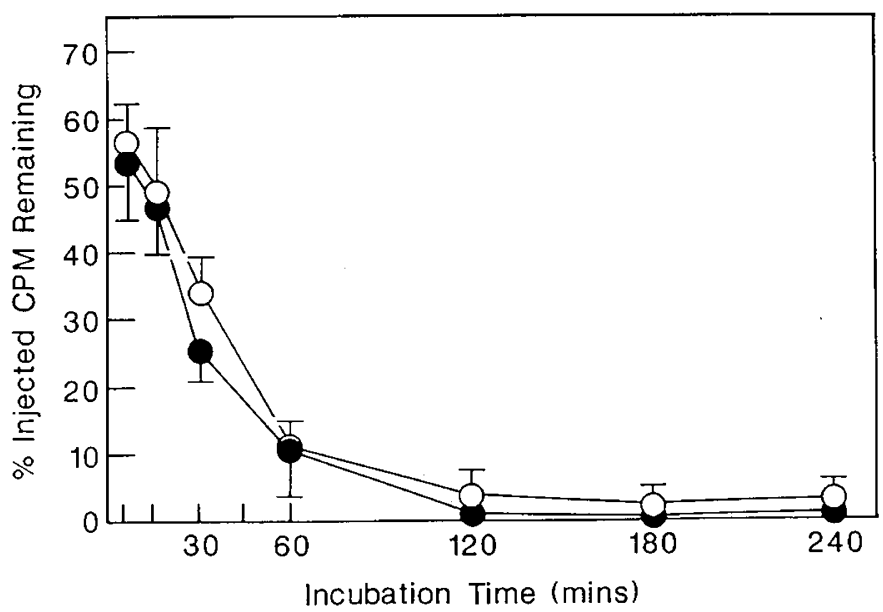

Fig. 5. Time course of disappearance of radioactivity from the jejunum of MAL (open circles) and FF (filled circles) rats. At various times, the fluid remaining in ligated loops was harvested, homogenized in an equal volume of ice-cold trichloroacetic acid, and centrifuged for $30 \mathrm{~min}$ at $40000 \times g$. Radioactivity remaining in the supernatant was compared with the amount of radioactivity initially injected into the loop and expressed as the percentage of injected cpm remaining. Data are mean \pm SEM of three to 11 separate determinations. 
FULLY FED
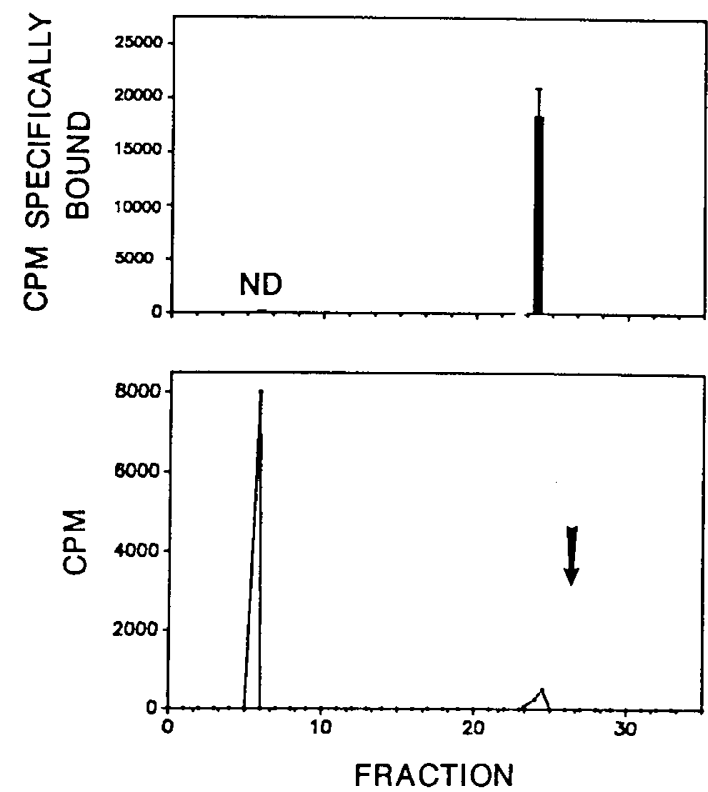

MALNOURISHED
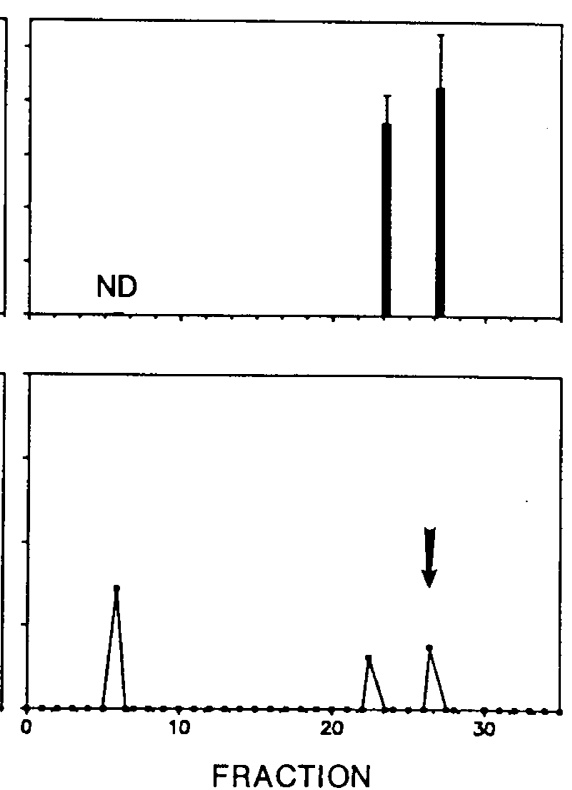

Fig. 6. HPLC profile and BBM binding activity of radioactivity remaining after $30 \mathrm{~min}$ of in situ incubation in FF and MAL rat jejunum. Arrows point to the HPLC retention time of unmodified 4-Tyr- ${ }^{125} \mathrm{I}_{\mathrm{ST}}$. A representative chromatogram from FF rats is shown on the left and from MAL rats on the right. Above each chromatogram is shown the BBM binding activity of the corresponding radioisotopic HPLC peak. Data are expressed as mean \pm SEM of three separate determinations. Binding data are expressed in cpm specifically bound per $100 \mu \mathrm{g}$ BBM protein after a 1 -h incubation at $37^{\circ} \mathrm{C}$ (see Materials and Methods). $N D$, no binding detected.

of diarrheal illness $(9-11,36)$. Our data provide evidence for an increased and prolonged secretory response to $\mathrm{ST}_{\mathrm{a}}$ in the jejunum of the malnourished rat. Our pair-feeding model produced total calorie deficiency corresponding to severe malnutrition, defined as a body weight $<60 \%$ of the expected weight for age (37). This degree of malnutrition produced diminished intestinal weight and length as well as changes in intestinal protein content and cellularity (DNA content). We have, therefore, where possible, normalized data in several different ways to minimize the effects of these variables.

To determine the mechanism for this prolonged secretory response to $\mathrm{ST}_{\mathrm{a}}$, we examined the possibility that there were malnutrition-associated increases in the avidity of $\mathrm{ST}_{a}$ binding, the number of toxin receptors, or the responsiveness of guanylate cyclase to $\mathrm{ST}_{\mathrm{a}}$. Our findings of identical binding of $\mathrm{ST}_{\mathrm{a}}$ and identical dose response curves for $\mathrm{ST}_{\mathrm{a}}$-mediated guanylate cyclase activation in MAL and FF do not support the hypothesis that these factors are involved in the increased response of the malnourished jejunum to $\mathrm{ST}_{\mathrm{a}}$. We observed an increase in jejunal differentiation or maturation in MAL as measured by an increase in sucrase activity similar to that which had been reported by others $(20,38)$. This increase in sucrase activity also serves as a control for the binding ability of $\mathrm{ST}_{\mathrm{a}}$ to its receptor, which is also localized to the BBM. In this model, the ability of the jejunum to absorb a saline control injection was also similar in MAL and FF. Thus, the increase in net secretion was not due to decreased basal absorption. This finding is also consistent with the presence of equally or more mature enterocytes despite the atrophic nature of the malnourished intestine (39).

The recent demonstration that guanylate cyclase is a receptor for $\mathrm{ST}_{\mathrm{a}}$ fits with our observations of parallel $\mathrm{ST}_{\mathrm{a}}$ binding and $\mathrm{ST}_{\mathrm{a}}$-induced guanylate cyclase activation in both groups (31). The possibility remains that increased intracellular accumulation of cGMP could provide an explanation for the enhanced secretory response in MAL. We did not measure the accumulation of cGMP, which would be affected by phosphodiesterase activity (degradation) as well as guanylate cyclase activity activation (production).
We also investigated the possibility that different patterns of inactivation of $\mathrm{ST}_{a}$ might explain the increased secretory response in the malnourished jejunum. In both MAL and FF, there was modification of the injected radiotracer. However, the degree of modification and inactivation of the injected radiotracer $\left(4-\mathrm{Tyr}^{-125} \mathrm{I}_{-}-\mathrm{ST}_{\mathrm{a}}\right)$ was greater in FF. A modified, inactive radiotracer accounted for $>98 \%$ of the remaining radioactivity in FF at 30 min of incubation. Two different ligands, both able to bind to BBM, together accounted for $38 \%$ of the remaining radioactivity in MAL. Although we did not determine the nature of the modification of $\mathrm{ST}_{\mathrm{a}}$ that resulted in the generation of the distinct HPLC profiles, each of the HPLC peaks must have retained the $4-\mathrm{Tyr}^{-125}{ }^{12}$ site to have been detected. We also demonstrated a correlation between the persistence of biologic activity in the suckling mouse assay and the time course of jejunal secretion in MAL and FF. We have previously demonstrated a correlation between persistent secretion, the continued presence of unmodified ${ }^{125} \mathrm{I}_{-} \mathrm{ST}_{\mathrm{a}}$, and biologic activity of fluid from the adult rat ileum in the suckling mouse assay (22). On the basis of these data, we suggest that the continued presence of active $\mathrm{ST}_{\mathrm{a}}$ in MAL jejunum at $\geq 30 \mathrm{~min}$ may contribute to the increased and prolonged secretory response to $\mathrm{ST}_{\mathrm{a}}$.

Recently, Young and Levin (38) demonstrated that acute starvation $(\leq 72 \mathrm{~h})$ made the rat jejunum hypersensitive to cholinergic and other stimuli. Thus, the possibility exists that the malnourished jejunum is hypersensitive as a result of a final common effect on chloride channel secretion, regardless of the stimulus. However, our observation of a prolonged secretory response to $\mathrm{ST}_{\mathrm{a}}$ differs somewhat from the observations of Young and Levin, who described a greater secretory response in the starved jejunum with a similar duration of secretion.

If reduced or delayed inactivation of $\mathrm{ST}_{\mathrm{a}}$ occurs in the intestine of the malnourished human infant, this might result in more prolonged or severe diarrheal illness. Other mechanisms may also be involved in the increased secretory response to bacterial enteropathogens observed in childhood malnutrition. These mechanisms include diminished immune competence (40), vitamin A deficiency (41), mucin depletion (20), decreased gastric 
acid secretion (42), and delayed intestinal repair (43). These mechanisms would further augment the increased secretory response to ETEC resulting from impaired host defense against $\mathrm{ST}_{\mathrm{a}}$, i.e. toxin inactivation.

In summary, antecedent malnutrition predisposes to an increased duration of diarrheal disease in children. We have studied the response of the malnourished rat jejunum to one of the most common causes of endemic diarrhea in children. We found an increased responsiveness of the malnourished rat jejunum to $\mathrm{ST}_{\mathrm{a}}$, and we examined several possible mechanisms to explain this increased responsiveness. Our data best support the possibility that impairment of intestinal inactivation of $\mathrm{ST}_{\mathrm{a}}$ contributes to an increase in $\mathrm{ST}_{\mathrm{a}}$-mediated secretion in the malnourished rat jejunum.

Acknowledgments. The authors thank T. Shumate for help in preparing the manuscript, Dr. E. Mann for preparing the rat guanylate cyclase cDNA clone and providing the oligonucleotide probe to $18 \mathrm{~S}$ ribosomal RNA, Dr. A. G. Mezoff for assistance in performing the guanylate cyclase assays, and Dr. W. F. Balistreri for his critical review of the manuscript.

\section{REFERENCES}

1. Black RE, Brown KM, Becker S, Yunus M 1982 Longitudinal studies of infectious diseases and physical growth in rural Bangladesh: I. patterns of morbidity. Am J Epidemiol 115:305-314

2. Black RE, Merson MH, Rahman AS, Yunus M, Alim AR, Huq I, Yolken RH, Curlin GT 1980 A two year study of bacterial, viral and parasitic agents associated with diarrhea in rural Bangladesh. J Infect Dis 142:660-664

3. Chen LC, Rahman M, Sarder AM 1980 Epidemiology and causes of death among children in a rural area of Bangladesh. Int $J$ Epidemiol 9:25-33

4. Walsh JA, Warren KS 1979 Selective primary health care: an interim strategy for disease control in developing countries. N Engl J Med 30:967-974

5. Snyder JD, Merson MH 1982 The magnitude of the global problem of acute diarrheal disease: a review of active surveillance data. Bull WHO 60:605613

6. El Samani EFZ, Willett WC, Ware JH 1988 Association of malnutrition and diarrhea in children aged under five years. Am J Epidemiol 128:93-105

7. Sepulveda J, Willett W, Munoz A 1988 Malnutrition and diarrhea: a longitudinal study among urban Mexican children. Am J Epidemiol 127:365-376

8. Schorling JB, McAuliffe JF, De Souza MA, Guerrant RL 1990 Malnutrition is associated with increased diarrhoea incidence and duration among children in an urban Brazilian slum. Int J Epidemiol 19:728-735

9. Black RE, Brown KH, Becker S 1984 Malnutrition is a determining factor in diarrhoeal duration, but not incidence, among young children in a longitudinal study in rural Bangladesh. Am J Clin Nutr 39:87-94

10. James JW 1972 Longitudinal study of the morbidity of diarrhoeal and respiratory infections in malnourished children. Am J Clin Nutr 25:690-694

11. Bairagi R, Chowdury MK, Kim YJ, Curlin GT, Gray RH 1987 The association between malnutrition and diarrhoea in rural Bangladesh. Int J Epidemiol 16:477-481

12. Donta ST, Wallace RB, Whipp SC, Olarte J 1977 Enterotoxigenic Escherichia coli and diarrheal disease in Mexican children. J Infect Dis 135:482-485

13. Guerrant RL, Moore RA, Kirshen PM, Sande MA 1975 Role of toxigenic and invasive bacteria in acute diarrhea of childhood. N Engl J Med 293:567-573

14. Levine MM, Caplan ES, Waterman D, Cash RA, Hornick RB, Snyder MJ 1977 Diarrhea caused by Escherichia coli that produce only heat-stable enterotoxin. Infect Immun 17:78-82

15. Field M, Graf LH, Laird WJ, Smith PL 1978 Heat stable enterotoxin of Escherichia coli: in vitro effects on guanylate cyclase activity, cyclic GMP concentration, and ion transport in small intestine. Proc Natl Acad Sci USA 75:2800-2804

16. Giannella RA, Luttrell M, Thompson M 1983 Binding of Escherichia coli heat-stable enterotoxin to receptors on rat intestinal cells. Am J Physiol 245:G492-G498
17. Cohen MB, Guarino A, Shukla R, Giannella RA 1988 Age-related differences in receptors for Escherichia coli heat-stable enterotoxin in the small and large intestine of children. Gastroenterology 94:367-373

18. Staples JS, Asher SE, Giannella RA 1980 Purification and characterization of heat-stable enterotoxin produced by a strain of $E$. coli pathogenic for man. J Biol Chem 255:4716-4721

19. Thompson MR, Luttrell M, Overmann G, Giannella RA 1985 Biological and immunological characteristics of ${ }^{125} \mathrm{I}-E$. coli heat-stable enterotoxin species purified by HPLC. Anal Biochem 148:26-36

20. Sherman P, Forstner J, Roomi N, Khatri I, Forstner G 1985 Mucin depletion in the intestine of malnourished rats. Am J Physiol 248:G418-G423

21. Cohen MB, Moyer MS, Luttrell M, Giannella RA 1986 The immature rat small intestine exhibits an increased sensitivity and response to Escherichia coli heat stable enterotoxin. Pediatr Res 20:555-560

22. Cohen MB, Thompson MR, Giannella RA 1989 Differences in jejunal and ileal response to $E$. coli enterotoxin: possible mechanisms. Am J Physiol 257:G118-G123

23. Giannella RA 1976 Suckling mouse model for detection of heat-stable Escherichia coli enterotoxin: characteristics of the model. Infect Immun 24:19-23

24. Schmitz J, Preiser H, Maestracci D, Ghosh BK, Cerda JJ, Crane RK 1973 Purification of human intestinal brush border membrane. Biochem Biophys Acta 323:98-112

25. Lowry OH, Rosebrough H, Farr AL, Randall RJ 1951 Protein measurement with the Folin phenol reagent. J Biol Chem 193:265-275

26. Brunk CV, Jones KC, James TW 1979 Assay for nanogram quantities of DNA in cellular homogenates. Anal Biochem 92:497-500

27. Munson PJ, Rodbard D 1980 Ligand: a versatile computerized approach for characterization of ligand-binding systems. Anal Biochem 107:220-239

28. Waldman SA, O'Hanley PD, Falkow S, Schoolnick G, Murad F 1984 A simple, sensitive and specific assay for the heat-stable enterotoxin of Escherichia coli. Infect Dis 149:83-89

29. Giannella RA 1976 Suckling mouse model for detection of Escherichia coli enterotoxin: characteristics of the model. Infect Immun 14:95-99

30. Chomczynski P, Sacchi N 1987 Single-step method of RNA isolation by acid guanidinium thiocyanate-phenol-chloroform extraction. Anal Biochem 162:156-159

31. Schulz S, Green CK, Yuen PST, Garbers DL 1990 Guanylyl cyclase is a heatstable enterotoxin receptor. Cell 63:941-948

32. Sanger F, Nicklen S, Coulson A 1977 DNA sequencing with chain-terminating inhibitors. Proc Natl Acad Sci USA 74:5463-5467

33. Church GM, Gilbert W 1984 Genomic sequencing. Proc Natl Acad Sci USA 81:1991-1995

34. Feinberg AP, Vogelstein B 1983 A technique for radiolabeling DNA restriction endonuclease fragments to high specific activity. Anal Biochem 132:6-13

35. Mann EA, Lingrel JB 1991 Developmental and tissue-specific expression of rat T-kininogen. Biochem Biophys Res Commun 174:417-423

36. Palmer DL, Koster FT, Alam AK, Islam MR 1976 Nutritional status: a determinant of severity of diarrhea in patients with cholera. J Infect Dis 134:8-14

37. Torun B, Viteri FF 1988 Protein-energy malnutrition. In: Shils ME, Young VR (eds) Modern Nutrition in Health and Disease. Lea \& Febiger, Philadelphia, pp 746-773

38. Young A, Levin RJ 1990 Diarrhoea of famine and malnutrition: investigations using a rat model. 1. Jejunal hypersecretion induced by starvation. Gut 31:43-53

39. Ribeiro Jr HC, Teichberg S, McGarvey E, Lifshitz F 1987 Quantitative alterations in the structural development of jejunal absorptive epithelial cells and their subcellular organelles in protein-energy-malnourished rats: a stereologic analysis. Gastroenterology 93:1381-1392

40. Lichtman SN, Sherman PM, Forstner GG 1988 Effect of dietary restriction on total and bacterium-specific mucosal secretory immunoglobulin A in bilediverted intestinal self-filling blind loops. Infect Immun 56:395-399

41. Levin RJ, Nzefwu H 1990 Vitamin A deficiency and its effects on in vitro jejunal and ileal electrogenic secretion in the rat. J Physiol 422:66

42. Gilman RH, Partanen R, Brown KH, Spira WM, Khanam S, Greenberg B, Bloom SR, Ali A 1988 Decreased gastric acid secretion and bacterial colonization of the stomach in severely malnourished Bangladeshi children. Gastroenterology 94:1308-1314

43. Butzner JD, Gall DG 1988 Effects of chronic protein-calorie malnutrition on small intestinal repair after an acute bacterial enteritis: a study in infant rabbits. Pediatr Res 23:408-413 